\title{
Short Communication: Investigating gonad length and fecundity in mudskippers (Gobiidae) at the Musi River estuary, South Sumatra, Indonesia
}

\author{
MOH. RASYID RIDHO ${ }^{1, \bullet}$, ENGGAR PATRIONO ${ }^{1}$, DINA RAHMAWATI ${ }^{1}$, RAHMAT PRATAMA ${ }^{1}$, \\ MUHAMMAD AVESENA ${ }^{2}$ \\ ${ }^{1}$ Department of Biology, Faculty of Mathematics and Natural Sciences, Universitas Sriwijaya. Jl. Raya Palembang-Prabumulih Km. 32, Indralaya, Ogan \\ Ilir 30662, South Sumatra, Indonesia. Tel.: +62-711-580056, Fax.: +62-711-580268, ^email: moh.rasyidridho@mipa.unsri.ac.id \\ ${ }^{2}$ Department of Aquaculture, Faculty of Fisheries and Marine Sciences, Universitas Diponegoro. J1. Prof. Sudarto No. 13, Tembalang, Semarang 50275, \\ Central Java, Indonesia
}

Manuscript received: 4 May 2021. Revision accepted: 25 September 2021

\begin{abstract}
Ridho MR, Patriono E, Wati DR, Pratama R, Avesena M. 2021. Short Communication: Investigating gonad length and fecundity in mudskippers (Gobiidae) at the Musi River estuary, South Sumatra, Indonesia. Biodiversitas 22: 4413-4420. Information on the biological aspects of mudskipper (Gobiidae) reproduction is needed as a conservation effort to use economically valuable and sustainable resources in the future. This can be used to enrich the information on the status of the mudskipper research at the Musi River estuary, South Sumatra, Indonesia. The field sampling was carried out by using the purposive sampling method. The sampling of fish was carried out by the researchers and assisted by the people of the community using fishing rods and bubu fish traps. The results showed that 122 mudskippers were obtained, which consisted of four species Boleophthalmus boddarti, Boleophthalmus dussumieri, Periophthalmus chrysospilos, Periophthalmodon schlosseri. 93 male and 29 female fish were caught, the sex ratio was 3.20:1. There are more male than female fish overall with the sampling method used. Most of the female fish fecundity was reported in P. chrysospilos, namely 23,270-36,264 items in GM (III) and ranged from 40,825-87,749 items in GM (IV). The largest egg diameter was reported in $P$. chrysospilos by 0.051-0.069 mm (GML III) and 0.053-0.062 mm (GML IV), while the smallest weight and length were reported in $P$. chrysospilos than other species. The egg size was not positively correlated with body size.
\end{abstract}

Keywords: Boleophthalmus, mudskipper, GM, GMI, sex ratio, Periophthalmus

\section{INTRODUCTION}

Mudskippers are taxonomically categorized into the Gobiidae family and Oxudercinae subfamily (Ishimatsu and Graham 2011). This fish is known internationally as the mudskipper (Lee et al. 1995), while it has several local names, such as gelodok, glodok, belodok, blodok, belodog, blodog, tembakul, tempakul, timpul, belaca, black kingfish, and lunjat. Muhtadi et al. (2016). Furthermore, the fish is named mudskipper because it lives in muddy habitat (Sayer 2005; Dinh 2017). Similarly, a skipper (mudskipper and rock skipper) is a group of amphibious fishes that can move freely from the ground to the water without the tide's influence (Ansari et al. 2014; You et al. 2018).

Mudskippers provide benefits for humans as a source of food and fish bait. Furthermore, it is believed that the fish can improve people's strength and therefore it is often consumed by pregnant women Kottelat et al. 1993; Kanejiya et al. 2017). In addition, the flesh has a high nutritional value (Andem and Ekpo 2014). In Bangladesh, China, Japan, Korea, Philippines, Taiwan, Thailand, and Vietnam some species are considered to have their delicacy and are cultivated extensively (Akinrotimi et al. 2013). Subsequently, this fish is consumed by fishermen as traditional medicine and can cure frequent urination in children (Muhtadi et al. 2016; Kanejiya et al. 2017; Ridho et al. 2020). However, the use of mudskippers in Indonesia is relatively low. Therefore, the information on the reproductive aspects of mudskipper is needed to enrich its status at the research site and to preserve as well as use the mudskipper resources that are economically valuable and sustainable in the future. In addition, this article is expected to enrich the information on the status of the mudskipper research at the Musi River estuary, Banyuasin District, South Sumatra, Indonesia.

According to Djumanto et al (2012); Bhakta et al. (2018), the information about the reproduction of a fish species can be used to determine fisheries policy, for example, the fishing season. However, fishing must respect the responsibilities of natural habitat and management of fish habitat. Therefore, research on the biological aspects of the mudskipper reproduction at the Musi River estuary of Sungsang II Village, Banyuasin District, South Sumatra is important. This research is a new record for reproduction aspect of mudskipper in Sumatra.

\section{MATERIALS AND METHODS}

\section{Study area}

This research was carried out at the Musi River estuary of Sungsang II Village, Banyuasin District, South Sumatra, 
Indonesia; coordinate point: 2021' 55.4" S; 1040 53' 59.7' E (Figure 1) from March-April, 2018. Furthermore, the mudskipper sample was collected from the Musi River estuary of Sungsang II Village. The data analysis and observations were carried out at the Laboratory of Animal Physiology, Department of Biology, Faculty of Mathematics and Natural Sciences, Sriwijaya University, Indralaya, Indonesia.

\section{Procedures}

Collecting samples in the field

The collection of the fish samples on the field was carried out using a purposive sampling method. The sampling of fish was carried out by the researchers and assisted by the people of the community using fishing rods and bubu fish traps. Furthermore, it was carried out from morning till noon until the water receded. Based on observations, the mudskipper caught with a fishing rod and shrimp pieces as bait were species with an average size of over $10 \mathrm{~cm}$, while those caught using fish traps were small, and medium in size (average below $15 \mathrm{~cm}$ ). Furthermore, the mudskipper caught were collected as samples and placed into plastic jars, documented using a camera and ikejime methods of killing. Then, the samples were stored with $40 \%$ formalin, covered and labeled. The preserved mudskipper was then wrapped in gauze, which was tightened and tied on both right and left sides using a rubber band. The fish samples were placed into the cool box for further observation and analysis.
The environmental quality parameters were measured for each fish sampling. The data collected by water salinity was measured using a refractometer, while tidal heights were observed at the sampling location for 24 hours using tidal sticks. Furthermore, the acidity or $\mathrm{pH}$ of the water was measured with a $\mathrm{pH}$ meter. In addition, water temperature and DO were measured using DO meters, while the type of substrate was observed visually and grip hands, and substrate types were documented using DSRL cameras.

\section{Measurement procedure}

Measurement and weight-length relationships (Schreck and Peter 1990; Ridho et al. 2019)

$$
\mathrm{W}={ }_{\mathrm{a}} \mathrm{L}^{\mathrm{b}}
$$

Where:

$\mathrm{W}$ : weight of fish $(\mathrm{g})$;

L: Total fish length (mm);

a: intercept (intersection relationship the curve of the long-weight with the y axis);

b: slope

Determining the sex ratio (Ridho and Patriono 2016).

$X=\frac{\mathrm{M}}{\mathrm{F}}$

Where:

M: the sum of male fish;

F: the sum of female fish

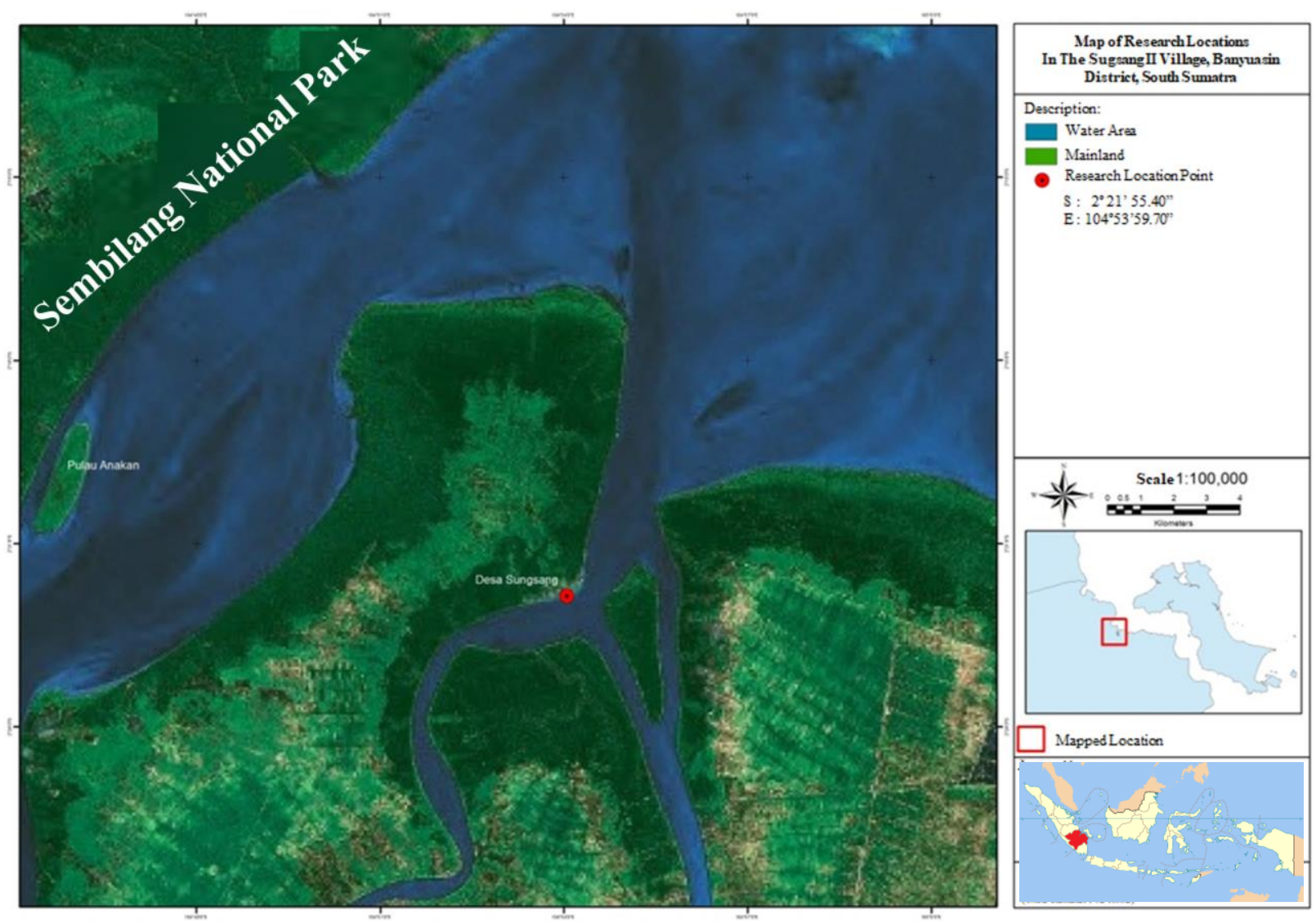

Figure 1. Mudskipper sampling site in Sungsang II Village, Banyuasin District, South Sumatra, Indonesia 
The level of gonad maturity (GML) (Schreck and Peter 1990)

The criteria for determining the level of gonad maturity (GML) of male and female mudskipper were carried out according to CB Schreck and Peter BM 1990 and by Djumanto et al. (2012).

The determination of gonad somatic index (GSI) (Schreck and Peter 1990; Kaban et al. 2019) is as follows:

$$
\mathrm{GSI}=\frac{\mathrm{GW}}{\mathrm{BW}} \times 100 \%
$$

Where:

GSI: Gonad Somatic Index (\%);

GW: Gonad weight (g);

BW: Bodyweight (g)

The observation of the level of gonad maturation (GML) of mudskipper was determined from the gonads removed from the body of the fish, the signs include the shape, size, color, and softness of the gonad's solidity.

The gonadal maturity level (GML) in mudskipper was determined based on Cassie's modified gonad morphology referred to by Effendie (1979). According to Effendie (1979), the features observed in the female fish are shape, size, color, smoothness, filling of the ovaries in the body cavity and size, clarity of shape, and color of eggs in the ovaries. While for male fish the features observed were the shape, size, color, and filling of the testes in the body cavity as well as the discharge of fluid from the testes (fresh condition).

\section{Calculation of fecundity}

The determination of fecundity was carried out by taking a mature ovary, the gonads in GML III and IV were soaked in Gilson solution. Furthermore, Gilson's solution can dissolve egg-wrapping tissues making it easier to calculate the number of eggs (fecundity) (Unus and Omar 2010). The observation of the level of gonad maturation (GML) of mudskipper was determined from the gonads removed from the body of the fish, the signs include the shape of the gonad, size, color, and the softness of the gonad's solidity. In addition, gonadal maturity level (GML) in mudskipper was determined based on Cassie's modified gonad morphology referred to by Effendie (1979). Fish fecundity was determined using the gravimetric method with the formula (CB Schreck and Peter BM 1990) as follows:

$$
F=\frac{G}{Q} x N
$$

Where:

F: fecundity (item);

$\mathrm{G}$ : body weight $(\mathrm{g})$;

Q: sample gonad weight (g); and

$\mathrm{N}$ : number of eggs in the gonad sample (item).

\section{Determination of egg diameter}

The determination of egg diameter was carried out on each part of the gonad to observe the difference in size distribution. The egg diameter was observed by collecting fish gonads estimated at GML III and IV. The gonads are removed and soaked in Gilson's solution. Each egg gonad was extracted from three parts namely posterior, median, and anterior, then the diameter was observed using a binocular microscope equipped with an ocular micrometer.

\section{Data analysis}

The data obtained were descriptive and analyzed by regression. The descriptive analysis was presented by figures and tables on the relationship between the weight and length of the fish caught. The relationship between the ratio and the level of gonadal maturity, gonadal development index, fecundity, and egg diameter as well as describing the spawning pattern of the fish. Furthermore, regression analysis was carried out on the weight-length relationship of samples of the fish caught.

\section{RESULTS AND DISCUSSION}

\section{Mudskipper sex ratio}

The number of mudskippers that have been caught were 93 male and 29 female in such a way that the overall sex ratio showed 1: 3.20 (Table 1).

Sex ratio conditions $(1: 2.5 ; 1: 3)$ represent one male fish gonad mature in a month, which must fertilize the eggs of three gonads mature female fish released into the waters (Siby et al. 2009; Wang et al. 2013). Generally, egg production from one female is relatively large in such a way that sperm from male fish require more than one tail for fertilization (Breder and Rosen 1966; Nasution et al. 2016).

\section{Length distribution of mudskipper (male and female)}

A total of 122 mudskippers were caught. Taxonomic identification classified the samples into four species, namely $B$. boddarti, B. dussumieri, $P$. chrysospilos, and $P$. schlosseri (Pormansyah et al. 2019). The distribution of mudskipper species was also reported in Indonesian waters, namely $B$. boddarti recorded in Sumatra, Kalimantan (Indonesian Borneo), Java, Sulawesi, Moluccas, Lesser Sunda; $P$. chrysospilos recorded at Sumatra, Java, and $P$. schlosseri recorded at Sumatra, Kalimantan (Indonesian Borneo), Java, Sulawesi, Moluccas, Lesser Sunda, Papua (West Papua, Indonesian Papua) (Pormansyah et al. 2019). mudskipper obtained consists of 93 males and 29 females. Based on the analysis performed, the distribution of the total length of the mudskipper in each species was obtained and can be seen in Figure 2.

Table 1. The total number of mudskipper caught during the research from March to April 2018

\begin{tabular}{llccc}
\hline Species & Mount & Male & Female & Total \\
\hline B. boddarti & March 2018 & 6 & 0 & 6 \\
& April 2018 & 36 & 8 & 44 \\
B. dussumieri & March 2018 & 2 & 1 & 3 \\
& April 2018 & 11 & 2 & 13 \\
P. chrysospilos & March 2018 & 0 & 0 & 0 \\
& April 2018 & 23 & 10 & 33 \\
P. schlosseri & March 2018 & 3 & 0 & 3 \\
Total & April 2018 & 12 & 8 & 20 \\
Sex ratio & & 93 & 29 & 122 \\
\hline
\end{tabular}


From the results in Figure 2. It can be seen that the data on the frequency distribution of total length from male and female mudskipper $(B$. boddarti) ranges from 8-10.99. The frequency of the male fish is distributed at intervals of 8 to 19.99, while the frequency of the female fish is at intervals of 14 to 22.99. Similarly, based on long-class, the male and female fish ranges from 14-16.99 to 20-22.99 (Hui et al. 2019; Sunarni et al. 2019), which reduced the catch frequency because the fish caught are dominated by small fish that stand are evolving and have not yet reached the adult size. The frequency of male mudskipper ( $B$. dussumieri) has decreased from long class as above from 10 to 11.99 to $14-15.99$. Furthermore, it is different from the frequency of female mudskipper which has the same frequency in three long class intervals that are in the range of $8-9.99 \mathrm{~cm}, 12-13.99 \mathrm{~cm}$, and $16-17.99 \mathrm{~cm}$. The overall frequency of male fish is higher than that of female fish, this occurs because male fish are believed to be on muddy land around a hiding hole to guard their territory (Low et al. 1990; Ibáñez and O'Higgins 2011; Ishimatsu et al. 2007).

The frequency of male mudskipper ( $P$. chrysospilos) is higher than that of female fish. The frequency of male fish caught was in the long class hose of 7-10.99, the lowest frequency in the long interval class 10-10.99 amounted to one tail, while in the long as above class 11-11.99 no one was caught. In contrast to female fish caught from longclass hose 8-11.99. In general, female fish are longer than male fish. In mudskipper ( $P$. schlosseri) there are two longclass hoses, which have the same frequency as male mudskipper and female mudskipper, there is long class hoses of about 8-11.99 cm and 16-19.99 cm. P. schlosseri has a higher length of hose than the other three species because this species is a giant mudskipper (Mazlan and Rohaya 2008).

\section{The weight-length relationship of mudskipper}

Fish growth patterns can be determined from the regression relationship between the weight and length of the fish. The results of the analysis of the relationship between weight and length of fish (Table 2.) show that the values of the correlation coefficient $\left(R^{2}\right)$ at a certain amount suggest that weight gain can be explained by the amount of length gain through the regression relationship. The $\mathrm{R}^{2}$ value showed that each additional weight will be accompanied by an increase in the length of each observation (Muhtadi et al. 2016).

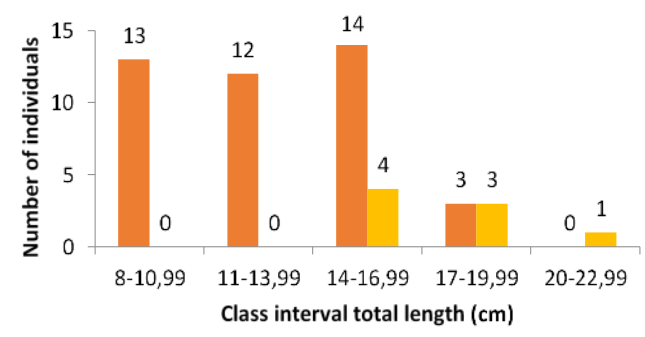

A

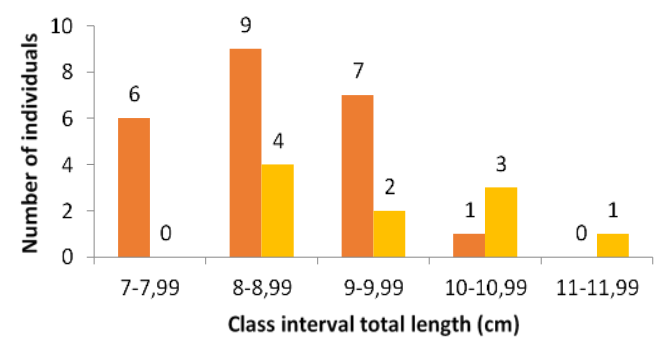

C

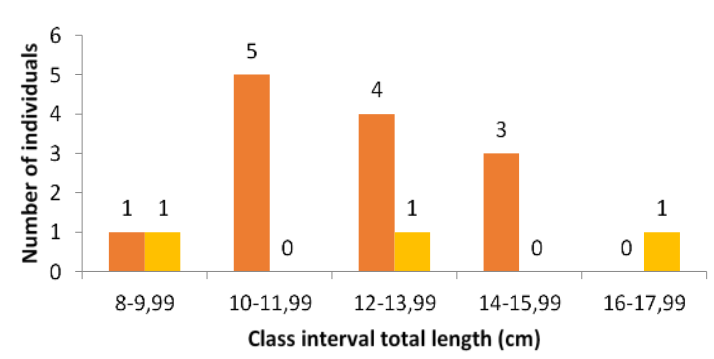

B

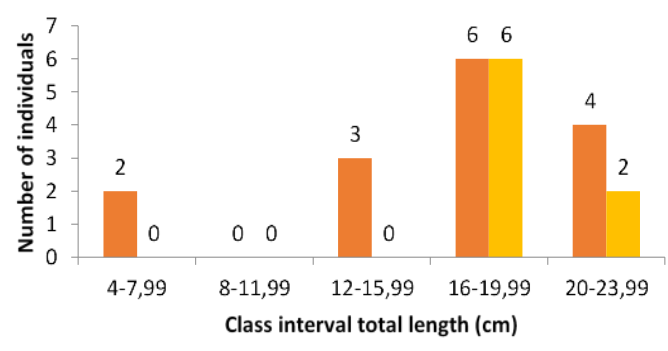

$\mathrm{D}$

Figure 2. Frequency distribution of the total length of the class interval (cm) during the study from March to April 2018 . A. Boleophthalmus boddarti, B. Boleophthalmus dussumieri, C. Periophthalmus chrysospilos, D. Periophthalmodon schlosseri

Table 2. Analysis of regression of the weight-length relationship of fish of each species

\begin{tabular}{llcccc}
\hline Species & $\mathbf{N}$ & W=aL & Growth pattern & $\mathbf{R}^{\mathbf{b}}$ & $\mathbf{r}^{\mathbf{2}}$ \\
\hline Boleophthalmus boddarti & 50 & $-28,466 \mathrm{~L}^{3.5968}$ & Positive allometric & 0.8528 & 0.923 \\
Boleophthalmus dussumieri & 16 & $-36,924 \mathrm{~L}$ 4.4046 & Positive allometric & 0.8717 & 0.933 \\
Periophthalmus chrysospilos & 33 & $-12,944 \mathrm{~L}^{2.1911}$ & Negative allometric & 0.8492 & 0.921 \\
Periophthalmodon schlosseri & 23 & $-68,532 \mathrm{~L}^{7.5037}$ & Positive allometric & 0.5832 & 0.763 \\
\hline
\end{tabular}


Based on the results of multiple regression tests that have been carried out on fish (B. boddarti, $P$. chrysospilos, $P$. schlosseri) to find out whether there is an effect or relationship between the independent variable weight and species length on the sex-dependent variable, it was found that there was a simultaneous and/or partial relationship which has a significant effect, with a value or magnitude of influence (regression coefficient) not more than $0.40(<40$ $\%)$. The regression coefficient values for Boleophthalmus boddarti were 0.320, Boleophthalmus dussumieri (0.017), Periophthalmus chrysospilos (0.265), and Periophthalmodon schlosseri (0.386). In contrast, the species in $B$. dussumieri did not show a significant simultaneous and/or partial relationship or effect, with a value or magnitude of effect (regression coefficient) of $0.017(1.7 \%)$. Thus it can be said that there is no relationship between the weight and length of the species to sex of fish, because the correlation coefficient value (R2) is less than $40 \%$. The cause does not have a significant effect on the relationship between the weight and length variables of the species on sex in multiple regression analysis of $B$. dussumieri species or other species caused by several factors, namely the redisu data is not normally distributed, the variable weight and length are not linearly related to the sex variable, the relationship between the two variable (species weight and length) is high or multicollinear, the scatter plot is not random but forms a line. In addition, according to Sari (2016), sex in fish has nothing to do with body length but is influenced by various factors, namely physical factors (temperature), chemical factors (dissolved oxygen and water acidity), and biological factors (amount and type of food).

\section{Gonad maturity level (GML) mudskipper}

Gonad maturity in fish also affects weight and length, as well as gonad weight. Based on the opinion of Nasution et al. (2016); Behera (2012), the increasing level of gonadal maturity in fish will certainly increase the volume of the gonad and increase the individual weight of the fish because the increased size of the egg diameter and weight of the gonad also increase.

The gonadal maturity level (GML) and the percentage of the number of fish in each species were different, in male B. boddarti species (26.88\%) and females $(17.24 \%)$ were mostly found in GML I stage, Boleophthalmus dussumieri GML I in males (6.45\%) ) and GML IV in females (6.90\%), $P$. chrysospilos GML III in males $(11.83 \%)$ and GML IV in females $(20.69 \%)$, P. schlosseri GML I in males $(5.38 \%)$ and females $(10.35 \%)$. Based on the maturity level of the gonad IV GML mudskipper caught from March-April, it can be estimated that fish are ready or have spawned. The percentage of frequency of male and female mudskipper IV GML in each species showed a percentage of about $20.69 \%$. The fish spawning season coincides with the rainy season, although local conditions also influence the spawning peaks (Sakamoto et al. 2015; Quang et al. 2015). The rainy season provides advantages with the availability of sufficient food for larvae and fish fry for survival and development (Siby et al. 2009). The female mudskipper will be in the nest during the spawning season. Fish nests are channels in soft, muddy sand that are used as nesting sites and other activities (Ansari et al. 2014), fish known as localized mudskipper make holes about 9 inches or $18-20 \mathrm{~cm}$.

\section{Gonad somatic index (GSI) mudskipper}

Table 3 shows that the gonad somatic index (GSI) of $B$. dussumieri, P. chrysospilos, and P. schlosseri has a higher average range of gonad somatic index (GSI) for females than male fish. This is known from the difference in analysis at one of the GML. Furthermore, GML IV on male B. dussumieri has a GSI of 0.9 and females of 1.68-3.12. GML IV on male $P$. chrysospilos was $1.85-1.87$ and female was 1.47-10.84. Similarly, the GML IV in male $P$. schlosseri was 0.4 and female was 2.05-3.24. According to Siby et al (2009), the GSI value of female fish is greater than that of male fish because the gonad weight of female fish is greater than that of male fish.

Table 3. Percentage (\%) of Gonad Somatic Index (GSI) of mudskipper during the study from March to April 2018

\begin{tabular}{|c|c|c|c|c|}
\hline Species & Sex & GML & $\begin{array}{c}\text { About GSI } \\
(\%)\end{array}$ & $\begin{array}{l}\text { Freq. } \\
\text { (ind.) }\end{array}$ \\
\hline \multirow{10}{*}{$\begin{array}{l}\text { Boleophthalmus } \\
\text { boddarti }\end{array}$} & \multirow[t]{5}{*}{ Male } & I & $0.42-3.46$ & 25 \\
\hline & & II & $0.49-1.04$ & 8 \\
\hline & & III & $0.26-1.25$ & 6 \\
\hline & & IV & $0.61-1.19$ & 3 \\
\hline & & $\mathrm{V}$ & 0 & 0 \\
\hline & \multirow[t]{5}{*}{ Female } & I & $0.44-0.75$ & 5 \\
\hline & & II & 0 & 0 \\
\hline & & III & 0 & 0 \\
\hline & & IV & 0 & 0 \\
\hline & & $\mathrm{V}$ & $0.44-0.73$ & 3 \\
\hline \multirow{10}{*}{$\begin{array}{l}\text { Boleophthalmus } \\
\text { dussumieri }\end{array}$} & \multirow[t]{5}{*}{ Male } & I & $1.27-4.11$ & 6 \\
\hline & & II & $0.90-1.32$ & 3 \\
\hline & & III & $0.32-0.62$ & 3 \\
\hline & & IV & 0.9 & 1 \\
\hline & & $\mathrm{V}$ & 0 & 0 \\
\hline & \multirow[t]{5}{*}{ Female } & I & 0 & 0 \\
\hline & & II & 0 & 0 \\
\hline & & III & 3.17 & 1 \\
\hline & & IV & $1.68-3.12$ & 2 \\
\hline & & $\mathrm{V}$ & 0 & 0 \\
\hline \multirow{10}{*}{$\begin{array}{l}\text { Periophthalmus } \\
\text { chrysospilos }\end{array}$} & \multirow[t]{5}{*}{ Male } & I & $3.13-3.93$ & 3 \\
\hline & & II & $2.95-4.67$ & 7 \\
\hline & & III & $2.01-5.06$ & 11 \\
\hline & & IV & $1.85-1.87$ & 2 \\
\hline & & V & 0 & 0 \\
\hline & \multirow[t]{5}{*}{ Female } & I & 0 & 0 \\
\hline & & II & 3.98 & 1 \\
\hline & & III & $5.18-12.58$ & 3 \\
\hline & & IV & $1.47-10.84$ & 6 \\
\hline & & $\mathrm{V}$ & 0 & 0 \\
\hline \multirow{10}{*}{$\begin{array}{l}\text { Periophthalmodon } \\
\text { schlosseri }\end{array}$} & \multirow[t]{5}{*}{ Male } & I & $0.59-9.36$ & 5 \\
\hline & & II & $0.25-0.36$ & 3 \\
\hline & & III & $0.26-0.38$ & 4 \\
\hline & & IV & 0.4 & 1 \\
\hline & & $\mathrm{V}$ & $0.13-0.26$ & 2 \\
\hline & \multirow[t]{5}{*}{ Female } & I & $0.46-0.52$ & 3 \\
\hline & & II & $2.98-3.16$ & 2 \\
\hline & & III & 2.44 & 1 \\
\hline & & IV & $2.05-3.24$ & 2 \\
\hline & & $\mathrm{V}$ & 0 & 0 \\
\hline
\end{tabular}


GML IV was not reported in female fish of $B$. boddarti. Therefore, the analysis of male GML IV and female GML V was analyzed, it was reported that in the GML V the GSI value experienced a decrease in the average range of GSI in GML IV for male fish at $0.61-1.19$, greater than that of the female GSI at GML V of 0.44-0.73. The gonad's weight attained its maximum when the fish spawn and decrease rapidly during spawning until it is complete (Schreck and Peter 1990; Wang et al. 2013). According to Siby et al. (2009), based on the level of gonad maturity, the GSI value of male and female fish increases with increasing GML, then the GSI value will decrease if spawning occurs because the weight of the gonad has decreased.

\section{Mudskipper fecundity}

Female mudskipper at maturity level III has different fecundities of each species. The fecundity of female fish counted in GML III has 1 gonad from $B$. dussumieri and $P$. schlosseri and 3 gonads from $P$. chrysospilos. The number of eggs in the ovaries of female fish can be seen from the fecundity. The smallest number of eggs was reported in $P$. schlosseri with up to 13.693 items, while the highest number of eggs was reported in $P$. chrysospilos with up to 23.270-36.264 items.

The difference in fecundity of the fish in GML III (Table 4.) and GML IV (Table 5.) occurred because it was influenced by internal and external factors. According to Ibáñez and O'Higgins (2011); Nasution et al. (2016), internal factors play a role that may change the age of the fish samples, gonad and fish that have repeatedly spawned for the first time due to genetic factors. The size of the parent, older and large size fish have relatively greater fecundity than younger fish.

\section{Diameters of mudskipper eggs}

The diameter of the female egg fish will increase from GML III to IV. The diameter of the egg in the front, middle and rear part of the GML III shows a significant difference, the diameter of the egg in the posterior part of GML IV can be considered to be mature and ready spawned by female fish. The pattern of the distribution of egg diameter is used as the basis for determining the spawning pattern of the frogfish. According to Nasution et al. (2016); Ridho and Patriono (2016), large eggs will be issued first, while small ones will follow.

Fecundity in GML III and GML IV based on the length of the highest egg diameter was in the Periophthalmodon chrysospilos species. The smallest egg diameter was reported in B. dussumieri at $0.034 \mathrm{~mm}$ (GML III) and 0.036-0.04 mm (GML IV). The largest egg diameter was reported in $P$. chrysospilos by 0.051-0.069 mm (GML III) and $0.053-0.062 \mathrm{~mm}$ (GML IV). Based on the size of the weight and length, $P$. chrysospilos has the smallest weight and length than the other species, but this does not affect the size of the egg diameter. According to Al-Kadhomity and Hughes (1988); Djumanto et al. (2012), egg diameters vary greatly depending on the length or weight of the parents. There was no tendency for the relationship between egg diameter and weight or length.

\section{Environmental quality parameters}

Based on Table 6 , the measurements and observations of the aquatic environmental parameters presented above are known to be useful in describing the water conditions that are suitable for the survival of mudskipper (Ansari et al. 2014). Kaban et al. (2018) state that environmental factors influence various forms of life in an organism. It is therefore very important to measure environmental factors in this research. The environmental factors that play an important role in the life of the organism are temperature, salinity, acidity $(\mathrm{pH})$, and dissolved oxygen content (DO).

Table 4. Female mudskipper Fecundity on GML III

\begin{tabular}{lccccc}
\hline Species & $\begin{array}{c}\text { Total length } \\
(\mathbf{c m})\end{array}$ & $\begin{array}{c}\text { Weight of body } \\
(\mathbf{g})\end{array}$ & $\begin{array}{c}\text { Sex of species } \\
\text { (GML) }\end{array}$ & $\begin{array}{c}\text { Weight of gonad } \\
\text { (g) }\end{array}$ & $\begin{array}{c}\text { Fecundity } \\
\text { (item) }\end{array}$ \\
\hline Boleophthalmus dussumieri & 9.45 & 7.4 & B (III) & 0.2343 & 15.223 \\
Periophthalmus chrysospilos & 8.35 & 5.4 & B (III) & 0.3186 & 26.932 \\
& 9.38 & 7.1 & B (III) & 0.3933 & 23.270 \\
& 10.01 & 8.6 & B (III) & 0.4456 & 36.264 \\
Periophthalmodon schlosseri & 18.49 & 56.6 & B (III) & 1.3806 & 13.693 \\
\hline
\end{tabular}

Table 5. Female mudskipper Fecundity on GML IV

\begin{tabular}{lccccc}
\hline Species & $\begin{array}{c}\text { Total length } \\
(\mathbf{c m})\end{array}$ & $\begin{array}{c}\text { Weight of } \\
\text { body }(\mathbf{g})\end{array}$ & $\begin{array}{c}\text { Sex of species } \\
\text { (GML) }\end{array}$ & $\begin{array}{c}\text { Weight of gonad } \\
(\mathbf{g})\end{array}$ & $\begin{array}{c}\text { Fecundity } \\
\text { (item) }\end{array}$ \\
\hline Boleophthalmus dussumieri & 12.26 & 18.7 & B (IV) & 0.5838 & 22.166 \\
& 16.5 & 29.2 & B (IV) & 0.4915 & 37.963 \\
Periophthalmus chrysospilos & 10.77 & 10.2 & B (IV) & 0.5071 & 83.535 \\
& 9.91 & 8.2 & B (IV) & 0.7097 & 56.893 \\
& 11.29 & 14.6 & B (IV) & 0.6449 & 87.749 \\
& 10.61 & 11.3 & B (IV) & 0.6110 & 81.819 \\
Periophthalmodon schlosseri & 8.44 & 6.4 & B (IV) & 0.694 & 40.825 \\
& 8.4 & 5.3 & B (IV) & 0.4905 & 52.665 \\
& 21.4 & 97.1 & B (IV) & 1.9936 & 25.863 \\
\hline
\end{tabular}


Table 6. Environmental condition the Musi River estuary of Sungsang II Village, Banyuasin District, South Sumatra during the study from March to April 2018.

\begin{tabular}{lcc}
\hline \multirow{2}{*}{ Parameters } & \multicolumn{2}{c}{ Month } \\
\cline { 2 - 3 } & March 2018 & April 2018 \\
\hline Water temperature $\left({ }^{\circ} \mathrm{C}\right)$ & 28.1 & 30.8 \\
Ph & 6.82 & 6.7 \\
DO (mg / L) & 4.1 & 6.2 \\
Salinity \%o & 0.1 & 0 \\
Basic substrate & Mud & Mud \\
\hline
\end{tabular}

The measurement results and tidal observations at the sampling location in March 2018 are presented in the picture above. Based on these results, it is known that tidal patterns are very volatile. The highest tide occurred at 2:34 a.m. WIB, the water level was $247 \mathrm{~cm}$. While the lowest ebb occurs at 20:34 WIB, the water level was $25 \mathrm{~cm}$. The mean water level (mean sea level) during March 2018 was $140.79 \mathrm{~cm}$.

Based on the data obtained, that the tidal conditions of the waters at the sampling location in April 2018 are quite volatile. The highest tide occurs at 1:02 a.m., the water level was $234 \mathrm{~cm}$. While the lowest ebb occurs for several hours, namely at 1:02 p.m. until 17:02 p.m., the water level was $18 \mathrm{~cm}$. The mean sea level during April was 106.83 $\mathrm{cm}$, lower than the tidal data for March.

Tide and water conditions during sampling greatly influence the number of mudskipper that can be caught (Polgar and Crosa 2009). When the tidal seawater is observed, the highest density of mudskipper in the coastal area was reported, and at low tide, the highest density of fish was reported in the river area. Therefore, information on tides is needed. Information on the gonad length and fecundity of mudskipper reproduction is needed as a conservation effort to use economically valuable and sustainable resources in the future. This can be used to enrich the information on the status of the mudskipper research at the Musi River estuary, South Sumatra, Indonesia.

\section{REFERENCES}

Akinrotimi OA, Edun OM, Uka A, Owhonda KN. 2013. Public Perception of mudskipper Consumption in Some Fishing Communities of Rivers State, Nigeria. J Fish Aquat Sci 8: 208-212. DOI: 10.3923/jfas.2013.208.212

Al-Kadhomity NK, Hughes GM. 1988. Histological study of different regions of the skin and gills in the mudskipper, Boleophthalmus boddarti with respect to their respiratory function. J Mar Biol Association of the United Kingdom 68: 413-422.

Andem AB, Ekpo PB. 2014. Proximate and Mineral Compositions of Mudskipper (Periophthalmus Babarus) in the Mangrove Swamp of Calabar River, Southern Nigeria. Int J Sci Tech 2: 72-76.

Ansari AA, Trivedi S, Saggu S, and Rehman H. 2014. Mudskipper: A biological indicator for environmental monitoring and assessment of coastal waters. J Entomol Zool Stud 2 (6): 22-33.

Behera S. 2012. Relationship among body weight, gonad weight, fecundity and Egg size of an ornamental fighting fish, betta splendens. Journal Bio Innov 1: 198-204.
Bhakta D, Meetei WA, Vaisakh G, Kamble S, Chanu TN, Das SK. 2018. Mudskipperery and Indigenous Fishing Devices in Narmada Estuary, Gujarat. J. Indian Soc Coastal Agric Res 36: 74-78.

Breder C, Rosen D. 1966. Modes of Reproduction in Fishes. Natural History Press, New York.

Dinh QM. 2017. Morphometric, growth and condition factor variations of Boleophthalmus boddarti in the Mekong delta, Vietnam. Iran J Fish Sci 16: 822-831.

Djumanto, Setyobudi E, Rudiansyah. 2012. Gelodok Fecundity, Boleophthalmus boddarti (Pallas 1770) on Brebes Beach. J Ich Indo 12: 59-71. DOI:10.32491/JII.V12I1.130

Effendie MI. 1979. Fisheries Biological Methods. Dewi Sri Foundation, Bogor. [Indonesian]

Hui NY, Mohamed M, Othman MNA, Tokiman L. 2019. Diversity and behaviour of mudskippers of Tanjung Piai, Pontian, Johor. IOP Conference Series: Earth and Env Sci 269: 012037. DOI: 10.1088/1755-1315/269/1/012037

Ibáñez AL, O’Higgins P. 2011. Identifying fish scales: The influence of allometry on scale shape and classification. J Fish Res 109: 54-60. DOI: 10.1016/j.fishres.2011.01.016

Ishimatsu A, Graham JB. 2011. Roles of Environmental Cues for Embryonic Incubation and Hatching in mudskippers. Integrative and Comparative Biology 51: 38-48. DOI: 10.1093/icb/icr018

Ishimatsu A, Yoshida Y, Itoki N, Takeda T, Lee HJ, Graham JB. 2007. mudskippers brood their eggs in air but submerge them for hatching. J. Exp. Biol 210: 3946-3954. DOI: 10.1242/jeb.010686

Kaban S, Armanto ME, Ridho MR, Hariani PL. 2018. Rapid Assessment of Water Quality in Teluk Lake by Using Macroinvertebrates (A Family Level Biotic Index). E3S Web of Conferences 68: 1-8. DOI: 10.1051/e3sconf /201868040

Kaban S, Armanto ME, Ridho MR, Hariani PL, Utomo AD. 2019. Growth pattern, reproduction and food habit of Palau fish Osteochilus vittatus in Batanghari River, Jambi Province, Indonesia. IOP Conference Series: Earth and Env Sci 348: 1-9. DOI: 10.1088/1755$1315 / 348 / 1 / 012015$

Kanejiya J, Solanki D, Beleem I, Gohil B. 2017. Nutrient content of three species of mudskipper (Gobiidae; Oxudercinae) in Bhavnagar coast, Gujarat, India. J. Zool. Stud 4: 48-51. ISSN 2348-5914

Kanejiya J, Solanki D, Beleem I, Gohil B. 2017. Mudskippers in the coast of Bhavnagar, Gulf of Khambhat, Gujarat, India. J. fish 5: 461-464. DOI:10.17017/jfish.v5i1.2017.179

Kottelat M, Whitten AJ, Kartikasari SN, Wirjoatmodjo S. 1993. Freshwater fishes of Western Indonesia and Sulawesi. Periplus Editions, Jakarta. [Indonesian]

Lee YJ, Choi Y, Ryu BS. 1995. A taxonomic revision of the genus Periophthalmus (Pisces: Gobiidae) from Korea with description of a new species. Ky J Ich 7: 120-127. ISSN 1225-8598.

Low WP, Ip YK, Lane DJW. 1990. A comparative study of the gill morphometry in the mudskippers Periophthalmus chrysospilos, Boleophthalmus boddarti and Periophthalmodon schlosseri. Zoological Science 7: 29-38.

Mazlan AG, Rohaya M. 2008. Size, growth and reproductive biology of the giant mudskipper, Periophthalmodon schlosseri (Pallas, 1770), in Malaysian waters. J App Ich 24: 290-296. DOI:10.1111/j.14390426.2007.01033.x

Muhtadi A, Ramadhani S, Yunasfi. 2016. Identification and Habitat Type of mudskipper (Family: Gobiidae) in Bali Beach, Batu Bara District, North Sumatra Province. Biospecies 9: 1-6. [Indonesian=

Nasution S, Ghalib M, Parnanda A. 2016. Maturity of the Gonad and mudskipper, Periophthalmmus variabilis Eggert, from Rupat Island Beach. J Fis Mar Affairs 21: 47-53. DOI: /10.31258/jpk.21.1.47-53

Polgar G, Crosa G. 2009. Multivariate characterisation of the habitats of seven species of Malayan mudskippers (Gobiidae: Oxudercinae). J. Mar. Bio 156: 1475-1486. DOI:10.1007/s00227-009-1187-0

Pormansyah, Iqbal M, Setiawan A, Yustian I, Zulkifli H. 2019. A Review of Recent Status on mudskippers (Oxudercine Gobies) in Indonesian Waters. Oceanography Fish Open Acc. J. 9: 555769. DOI: 10.19080/OFOAJ.2019.09.555769.

Quang DM, Giang NTT, Tien NTK. 2015. Reproductive Biology of The mudskipper Boleophthalmus boddarti In Soc Trang. Tap Chi Sinh Hoc 37: 362-369. DOI: 10.15625/0866-7160/v37n3.6720

Ridho MR, Patriono E. 2016. Food Habits and Feeding Habits of Barramundi Fish (Lates Calcarifer Block) in Terusan Dalam (Inside Canal) Waters, East Coast of South Sumatra Province. Biovalentia 2: 104-111. DOI: 10.24233/BIOV.2.2.2016.37 
Ridho MR, Patriono E, Sholikah M. 2019. Food habits of three species of mudskippers in the Musi River Estuary, South Sumatra, Indonesia. Biodiversitas 20: 2368-2374. DOI: 10.13057/biodiv/d200835

Ridho MR, Setiawan A, Sarno, Arwinsyah, Patriono E, Sulistiono. 2020 Bioactive Compounds Evaluation of the mudskippers in the Estuarine Area of Musi River, South Sumatera, Indonesia. J. Eco. Eng 21: 70 80. DOI: $10.12911 / 22998993 / 118296$

Sakamoto T, Nishiyama Y, Ikeda A, Takahashi H, Hyodo S, Kagawa N, Sakamoto H. 2015. Neurohypophysial hormones regulate amphibious behaviour in the mudskipper goby. PLoS ONE 10: 1-16. DOI 10.1371/journal.pone.0134605

Sari R.T. 2016. Hubungan panjang tubuh dan rasio papilla dengan jenis kelamin pada ikan gobi (Sicyopterus macrostetholepis Blkr.) J. Pend. Mat \& IPA, 7: 55-68

Sayer MDJ. 2005. Adaptations of amphibious fish for surviving life out of water. J F Fisheries 6: 186-211. DOI: 10.1111/j.14672979.2005.00193.x

Schreck CB, Peter BM. 1990. Methods for Fish Biology. American Fisheries Society Publication, USA.
Siby LS, MF Rahardjo, DS Sjafei. 2009. Reproduction Biology of Red Pelangi Fish (Glossolepis incisus, Weber 1907) at Lake Sentani. J. Ich. Indo 9: 49-61. DOI: 10.32491/jii.v9i1.201

Sunarni, Melmambessy EHP, Mote N, Rahmatia, Hamuna B. 2019. Length-Weight Relationship and Condition Factor of mudskipper Boleophthalmus pectinirostris from Maro Estuary, Merauke District, Papua J. Eco Eng 20: 199-204. DOI: 10.12911/22998993/110841

Unus F, Omar SBA. 2010. Analisis fekunditas dan diameter telur ikan malalugis biru (Decapterus macarellus Cuvier, 1833) di Perairan Kabupaten Banggai Kepulauan Propinsi Sulawesi Tengah. Ilmu Kelautan dan Perikanan 20 (1): 37-43. [Indonesian]

Wang L, Xu M, Liu B, Jiang T, Zhang S, Yang J. 2013. Experimental study on morphology and kinematics of mudskipper in amphibious environments. IEEE Int Conf Robot Biomim (ROBIO). Shenzhen, China, 12-14 December 2013.

You X, Sun M, Li J, Bian C, Chen J, Yi Y, Yu H, Shi Q. 2018. mudskippers and Their Genetic Adaptations to an Amphibious Lifestyle. J An 8: 2-12. DOI: 10.3390/ani8020024 